\title{
DOES RENAL DYSFUNCTION IMPROVE THE PREDICTIVE VALUE OF HATCH SCORE FOR POSTOPERATIVE ATRIAL FIBRILLATION?
}

\author{
Marija GJERAKAROSKA RADOVIKJ ${ }^{1 凶}{ }^{\text {, Galina SEVEROVA }}{ }^{2}$, Sashko JOVEV ${ }^{1}$ \\ ${ }^{1}$ State University Clinic of Cardiac Surgery, Faculty of Medicine, Skopje, Republic of North Macedonia \\ ${ }^{2}$ University Clinic of Nephrology, Faculty of Medicine, Skopje, Republic of North Macedonia
}

Received 03 Oct 2021, Accepted 11 Nov 2021

https://doi.org/10.31688/ABMU.2021.56.4.05

\begin{abstract}
Introduction. Postoperative atrial fibrillation (POAF) is a frequent arrhythmic complication in cardiac surgery. Studies of this potential complication have not been able to elucidate its etiology nor to identify the predictors of its occurrence.

The objective of the study was to evaluate the predictive role of renal dysfunction for POAF in patients undergoing cardiac surgery interventions. We also aimed to determine the role of renal dysfunction in improving diagnostic accuracy of Hypertension, Age, Transitory attack/stroke, Chronic obstructive pulmonary disease, Heart failure (HATCH) score for POAF.
\end{abstract}

Material and methods. This prospective monocentric observational study included 178 consecutive patients who underwent cardiac surgery interventions in the State University Clinic of Cardiac Surgery of Skopje, Republic of North Macedonia, between September 2017- September 2018. Patients were divided in two groups, according to the absence or occurrence of POAF. HATCH score was calculated and recorded for each patient. A new R-HATCH score was derived by addition of renal dysfunction to the existing

\section{Résumé}

Le dysfonctionnement rénal améliore-t-il la valeur prédictive du score HATCH pour la fibrillation auriculaire postopératoire?

Introduction. La fibrillation auriculaire postopératoire (FAPO) est une complication arythmique fréquente en chirurgie cardiaque. Les études de cette complication potentielle n'ont pas été en mesure d'élucider son étiologie or d'identifier les facteurs prédictifs de sa survenue.

L'objectif de l'étude était d'évaluer le rôle prédictif du dysfonctionnement rénal pour la FAPO chez les patients subissant des interventions de chirurgie cardiaque. Nous avons également cherché à déterminer le rôle de la dysfonction rénale dans l'amélioration de la précision diagnostique du score HATCH (qui associe l'hypertension (H), l'âge au-dessus de 75 ans (A), des antécédents d'accidents vasculaires cérébraux ou ischémiques transitoires $(\mathrm{T})$, une maladie pulmonaire chronique obstructive (C), et une défaillance cardiaque (H)) pour la FAPO.

Matériel et méthodes. Cette étude observationnelle monocentrique prospective a inclus 178 patients 
HATCH score and its predictive value for POAF was tested and compared to HATCH.

Results. POAF occurred in 90 of 178 patients $(50.56 \%)$. The average eGFR in the group developing POAF was significantly lower, $78.4 \pm 26.9$ vs $93.0 \pm 29.0$ $\mathrm{ml} / \mathrm{min} / 1,73 \mathrm{~m}^{2}(\mathrm{p}=0.0005)$. Patients with GFR $<60 \mathrm{ml} / \mathrm{min} / 1.73 \mathrm{~m}^{2}$ had almost a 5 times greater risk of developing POAF. The addition of renal dysfunction to HATCH score improved its predictive accuracy in our study. The area under the receiver operating characteristic curve increased from 0.73 to 0.76 ( $\mathrm{p}<$ 0.001).

Conclusions. The addition of preoperative renal dysfunction could improve the diagnostic accuracy of HATCH score for POAF.

Keywords: postoperative atrial fibrillation, renal dysfunction, HATCH score, cardiac surgery.

\section{Abbreviations:}

POAF - postoperative atrial fibrillation; $\mathrm{HATCH}$ Hypertension, Age, Transitory attack/stroke, Chronic obstructive pulmonary disease, Heart failure; HTN hypertension; TIA/CVA - transitory ischemic attack/ stroke, COPD - chronic obstructive pulmonary disease; AF - atrial fibrillation; MDRD - Modification of Diet in Renal Disease Study; eGFR- estimated glomerular filtration rate; BSA - body surface area; BMI - body mass index; HF - heart failure; CMP cardiomyopathy; DM2 - type 2 diabetes mellitus; PAD - peripheral artery disease; CKD - chronic kidney disease; $\mathrm{CABG}$ - Coronary artery by-pass grafting.

\section{INTRODUCTION}

Despite the significant advancements in surgical techniques, postoperative atrial fibrillation (POAF) remains a frequent arrhythmic complication in cardiac surgery ${ }^{1-4}$. Extensive studies of this potential and costly complication over the past decades have demonstrated the limited ability/performance to predict its occurrence ${ }^{5-8}$. Therefore, ongoing attempts to improve the accuracy of existing models is essential, to identify the high-risk subgroup of patients in whom prophylactic measures must be applied $^{9-11}$. The HATCH score has been described for the first time by De Vos et $\mathrm{a}^{12}$ and includes the following parameters: hypertension HTN (1 point), age above 75 years ( 1 point), transitory ischemic attack (TIA)/stroke (CVA) (2 points), chronic obstructive pulmonary disease (COPD) (1 point), heart failure (2 points). Analysing the individual risk factors, these authors concluded that HATCH score is a strong independent predictor of transition from paroxysmal consécutifs ayant subi une intervention de chirurgie cardiaque à la Clinique universitaire d'État de chirurgie cardiaque de Skopje, République de la Macédoine du Nord, entre septembre 2017 et septembre 2018. Les patients ont été divisés en deux groupes, selon l'absence ou l'occurence de FAPO. Le score HATCH a été calculé et enregistré pour chaque patient. Un nouveau score R-HATCH est dérivé en ajoutant le dysfonctionnement rénal au score $\mathrm{HATCH}$ existant et sa valeur prédictive pour la FAPO a été testée et comparée à HATCH.

Résultats. La FAPO est survenue chez 90 des 178 patients (50,56\%). La RFG moyenne dans le groupe développant FAPO était significativement plus faible, $78,4 \pm 26,9$ vs $93,0 \pm 29,0 \mathrm{ml} / \mathrm{min} / 1,73 \mathrm{~m}^{2}$ ( $\left.\mathrm{p}=0,0005\right)$. Les patients avec $R F G<60 \mathrm{ml} / \mathrm{min} / 1,73 \mathrm{~m}^{2}$ avaient un risque presque 5 fois plus élevé de développer FAPO. Lajout du dysfonctionnement rénal au score HATCH a amélioré sa précision prédictive dans notre étude. Laire sous la courbe caractéristique de fonctionnement du récepteur a augmenté de 0,73 à $0,76(\mathrm{p}<0,001)$.

Conclusions. L'ajout d'un dysfonctionnement rénal préopératoire pourrait améliorer la précision diagnostique du score HATCH pour la FAPO.

Mots-clés: fibrillation auriculaire, dysfonctionnement rénal, HATCH score, chirurgie cardiaque.

to permanent AF. HATCH score is also proven to be a simple and readily available clinical tool for POAF risk determination after coronary artery by-pass grafting (CABG). Several high-scale studies on the predictive role of comorbidities for POAF occurrence found renal dysfunction to be a significant POAF predictor $^{13,15-16}$. Since HATCH score does not include this potentially highly significant comorbidity, we aimed to investigate whether its inclusion would improve the predictive accuracy of HATCH for POAF.

The objective OF THIS StUdy was to evaluate the predictive role of renal dysfunction for POAF in patients undergoing cardiac surgery interventions. We also aimed to determine its additive role to improve diagnostic accuracy of HATCH score for POAF.

\section{Material ANd Methods}

This prospective monocentric observational study included 178 consecutive patients who 
Table 1. Preoperative demographics of patients with and without postoperative atrial fibrillation.

\begin{tabular}{cccc}
\hline & POAF $(+) \mathrm{N}=90$ & $\begin{array}{c}\text { POAF(-) } \\
\text { N=88 }\end{array}$ & p-value \\
\hline Age (years) & $67,21 \pm 8,41$ & $60.62 \pm 9.40$ & 0.003 \\
Sex (ref. female) & $33.3 \%$ & $34.09 \%$ & 0.914 \\
\hline BSA $\left(\mathbf{m}^{2}\right)$ & $1.87 \pm 0.19$ & $1.87 \pm 0.20$ & 0.996 \\
\hline BMI $\left(\mathrm{kg} / \mathrm{m}^{2}\right)$ & $28.22 \pm 4.57$ & $27.95 \pm 4.38$ & 0.337 \\
\hline Smokers & $45.56 \%$ & $45.45 \%$ & 0.989 \\
Comorbidities & & & 0.058 \\
HT & $10 / 9(11.11 \%)$ & $19 / 88(21.59 \%)$ & 0.223 \\
HF & $22 / 90(24.44 \%)$ & $15 / 88(17.05 \%)$ & 0.397 \\
CMP & $21 / 90(23.33 \%)$ & $16 / 88(18.18 \%)$ & 0.373 \\
DM2 & $31 / 90(34.44 \%)$ & $36 / 88(40.91 \%)$ & 0.245 \\
TIA/CVA & $12 / 90(13.33 \%)$ & $7 / 88(7.95 \%)$ & 0.490 \\
PAD & $19 / 90(21.11 \%)$ & $15 / 88(17.05 \%)$ & $0.0001^{*}$ \\
CKD & $50 / 90(55.56 \%)$ & $24 / 88(27.27 \%)$ & $0.00001^{*}$ \\
COPD & $55 / 90(66.11 \%)$ & $25 / 88(28.41 \%)$ & \\
\hline
\end{tabular}

Legend: Results are shown as mean \pm SD. BSA - body surface area, BMI - body mass index, HT - hypertension, HF - heart failure, CMP - cardiomyopathy, DM2 - type 2 diabetes mellitus, TIA/CVA-transitory ischemic attack/stroke, PAD - peripheral artery disease, CKD - chronic kidney disease, COPD - chronic obstructive pulmonary disease.

underwent cardiac surgery interventions in the State University Clinic of Cardiac Surgery of Skopje, Republic of North Macedonia, between September 2018- September 2019. The patients were divided in two groups, according to occurrence or absence of POAF (POAF (+) and POAF (-) group). The inclusion criteria in the study were age $>18$ years, indication for cardiac surgery intervention and absence of atrial fibrillation, signed informed consent, while exclusion criterium was age $<18$ years. Complete medical records were prospectively collected to investigate the relationships between demographic data, comorbidities, renal function and the risk of POAF after cardiac surgery. Blood samples were drawn the day before the cardiac surgery, for the measurement of serum creatinine. Renal dysfunction was defined as an estimated glomerular filtration rate (eGFR) of $<60$ $\mathrm{mL} / \mathrm{min} / 1.73 \mathrm{~m}^{2}$. Laboratory tests were obtained, to calculate the eGFR according to MDRD formula $(\mathrm{GFR}=186 \times$ serum creatinine $-1.154 \times$ age $-0.203 \times$ 1.212 (black) $\times 0.742(\text { female })^{13}$. The value of HATCH score was calculated and recorded for each patient ${ }^{12}$. Continuous electrocardiographic telemetry for the occurrence of POAF was obtained for each patient during the entire hospital stay. POAF was defined as an episode of sustained atrial fibrillation lasting $>30$ seconds, recorded by continuous electrocardiogram monitorization throughout hospitalization following cardiac surgery, as described previously ${ }^{1}$. This study was approved by the institutional review board for human subjects at our institution (approval no. 03-4314/3, date of approval 20.09.2018), and each patient signed an informed consent for participation in the study.
The statistical analysis was performed with SPSS software package, version 22.0 for Windows (SPSS, Chicago, IL, USA). The analysis of attributive (qualitative) series was done by determining the coefficient of relations, proportions and rates. Numerical series were analysed using central tendency and dispersion measures. Risk factors were quantified using odd ratio (OR) and confidence intervals (CI). Univariate and multiple logistic regression analysis, as well as Enter and Backward Conditional, were used to determine and quantify the independent significant predictors of POAF $(+)$ status. The difference between the area under the curve (AUC) of two receiver operating characteristic (ROC) curves was analysed with Mann-Whitney U test (Z/p). A p value $<0.05$ was considered statistically significant.

\section{Results}

The incidence of POAF in our study was 50.56\%. The median value of time to POAF occurrence was 2 (range 0-7) days postoperatively. Preoperative demographics of patients in both groups are presented in Table 1.

The patients in $\operatorname{POAF}(+)$ group were significantly older, with a mean age of $67.2 \pm 8.4$ vs $60.6 \pm 9.4$ years in the POAF(-)group (Mann-Whitney U Test: $\mathrm{Z}=-4.963, \mathrm{p}=0.00001)$. No significant gender difference was noted between the two groups $(p=0.914)$.

CABG was performed in 107 patients, aortic valve surgery in 127 patients, mitral valve surgery in 17 patients, Bentall procedure in 10 patients, ascending aorta replacement in 8 and left atrial myxoma removal in 2 patients. The statistical analysis showed a 
Table 2. Analysis according to POAF status and eGFR.

\begin{tabular}{|c|c|c|c|c|c|c|c|c|c|}
\hline \multirow{2}{*}{\multicolumn{2}{|c|}{ Parameters }} & \multirow{2}{*}{$\begin{array}{c}\text { Number } \\
\text { (N) }\end{array}$} & \multirow{2}{*}{ Average } & \multirow{2}{*}{$\begin{array}{l}\text { Standard } \\
\text { deviation }\end{array}$} & \multirow{2}{*}{ Min } & \multirow{2}{*}{$\operatorname{Max}$} & \multirow{2}{*}{ Median } & \multicolumn{2}{|c|}{$95 \%$ CI of mean } \\
\hline & & & & & & & & Lower & Upper \\
\hline \multirow{4}{*}{ eGFR } & $\operatorname{POAF}(+)$ & 90 & 78.38 & 26.95 & 10 & 156 & 77.00 & 72.73 & 84.02 \\
\hline & POAF(-) & 88 & 93.06 & 29.02 & 15 & 175 & 90.00 & 86.91 & 99.20 \\
\hline & Total & 176 & 85.63 & 28.86 & 10 & 175 & 84.50 & 81.37 & 89.90 \\
\hline & \multicolumn{4}{|c|}{ t-test $(176)=3.4983 ; p=0.0005^{*}$} & \multicolumn{3}{|c|}{ *significant for $p<0.05$} & & \\
\hline
\end{tabular}

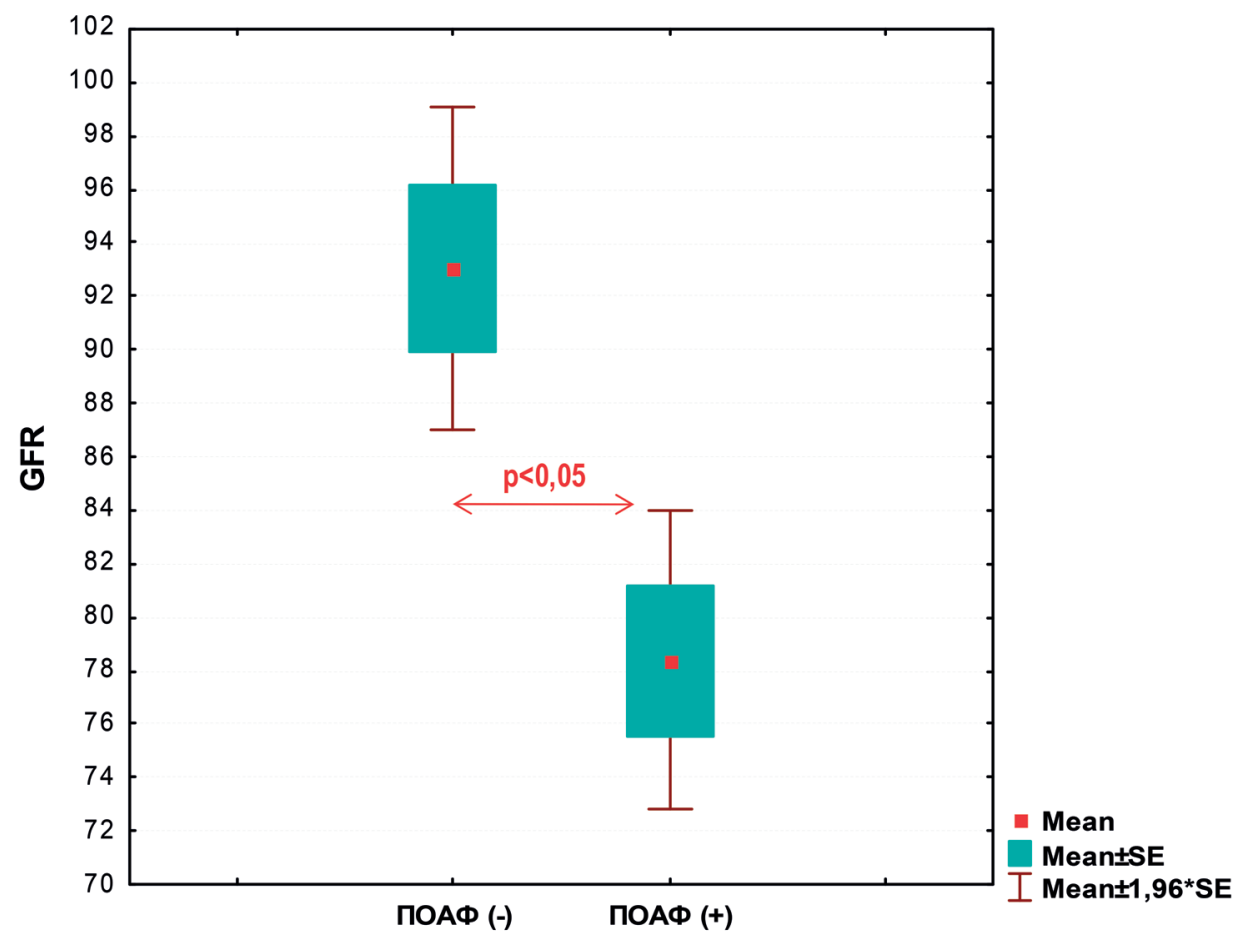

Figure 1. Analysis of POAF status according to eGFR $<60 \mathrm{ml} / \mathrm{min} / 1.73 \mathrm{~m}^{2}$

significant association between the POAF status and type of surgery only for mitral valve surgery. $\operatorname{POAF}(+)$ status was significantly more frequent after mitral valve surgery (Pearson Chi-square test $=7.5992, \mathrm{df}=1$, $\mathrm{p}=0.0058)$.

The patients in the POAF(+) group had multiple comorbidities. There was a significant association between the presence of COPD and POAF occurrence (Pearson Chi-square test=14.653, $\mathrm{df}=1, \mathrm{p}=0.0001$ ). Chronic kidney disease (CKD) was 3.33 times more often in the $\mathrm{POAF}(+)$ group of patient, $\mathrm{OR}=3.33[95 \%$ $\mathrm{CI}(1.78-6.23)]$.

\section{POAF and eGFR}

The mean eGFR value in the $\operatorname{POAF}(+)$ and POAF(-) group was $78.4 \pm 26.9$ [95\% CI (72.7-84.0)] vs $93.0 \pm 29.0 \mathrm{ml} / \mathrm{min} / 1,73 \mathrm{~m}^{2}$ [95\% CI (86.9-99.2)]. We found a significantly lower eGFR in the POAF(+) group compared to POAF(-) group [t-test (176)=-3.4983; $\mathrm{p}=0.0005]$ (Table 2).
Additionally, we performed the analysis of eGFR below and above $60 \mathrm{ml} / \mathrm{min} / 1.73 \mathrm{~m}^{2}$. An eGFR $<60$ $\mathrm{ml} / \mathrm{min} / 1.73 \mathrm{~m}^{2}$ was found in $24(26.7 \%)$ patients from the $\mathrm{POAF}(+)$ group vs $6(6.8 \%)$ patients from the POAF(-) group (Pearson Chi-square test=12.509, $\mathrm{df}=1, \mathrm{p}=0,0004)$. The eGFR $<60 \mathrm{ml} / \mathrm{min} / 1.73 \mathrm{~m}^{2}$ was 4.969 times more frequently found in the POAF(+) group, OR=4.969 [95\% CI (1.92-12.87)] (Fig. 1).

\section{POAF and HATCH score}

HATCH score ranges from 0 (no risk) to 7 (maximal risk). A HATCH score greater than 2 was more common in the POAF(+) group. In other words, patients developing POAF had higher values for $\mathrm{HATCH}$ score in comparison to patients without POAF. We found a significant association between $\mathrm{POAF}(+)$ status and the value of HATCH score (Fisher Feaman Halton exact test: $p=0.000008$ ) (Fig. 2).

One of the objectives of this study was to determine the predictive role of HATCH for POAF. 


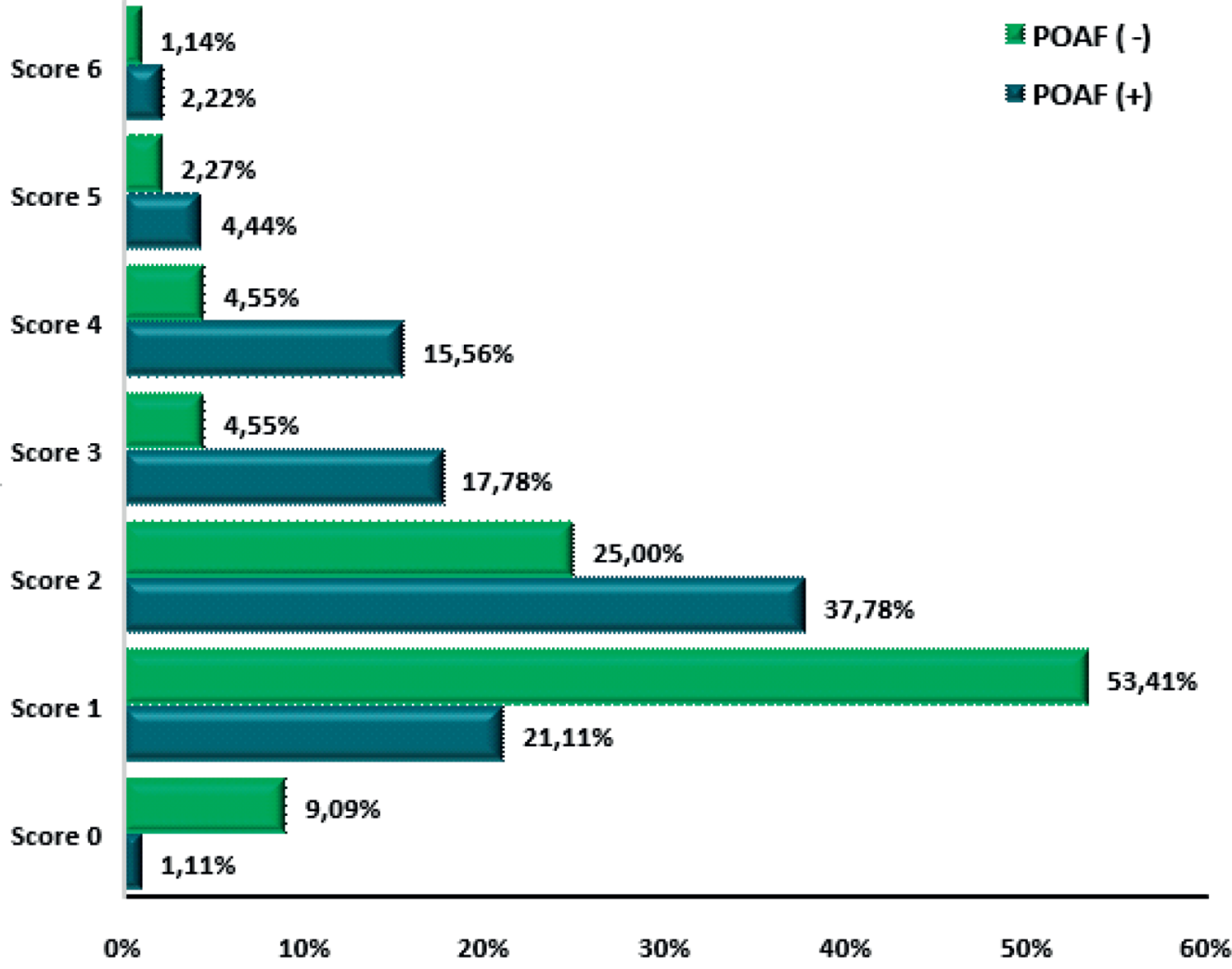

Figure 2. Association between POAF status and HATCH score.

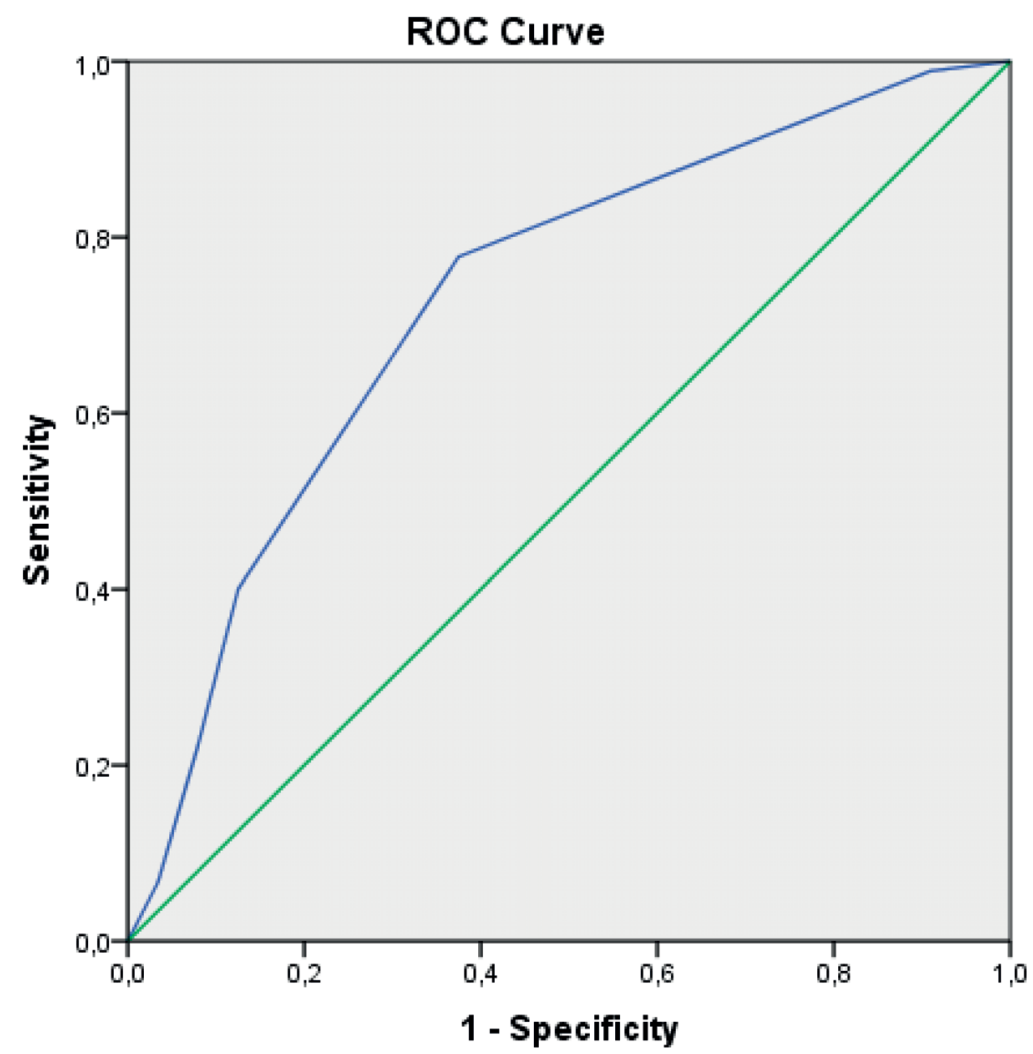

Diagonal segments are produced by ties.

Figure 3. Univariate logistic regression analysis of HATCH score for POAF. 


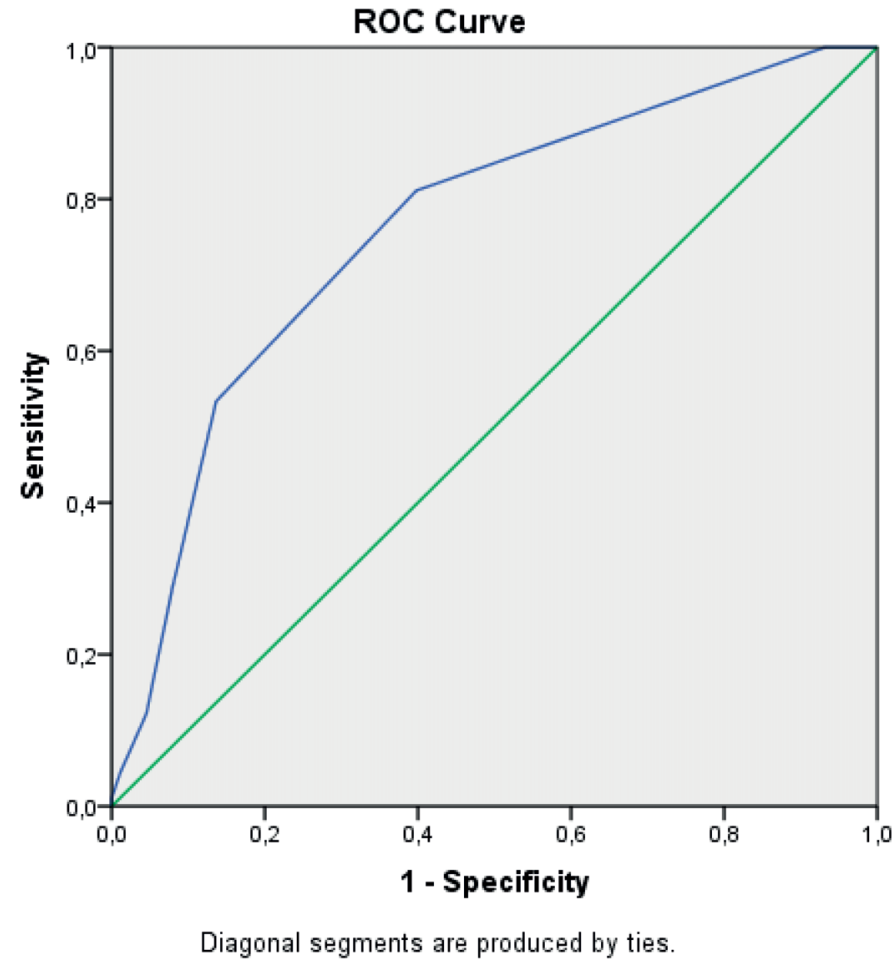

Figure 4. Univariate logistic regression analysis of R-HATCH score for POAF.

Table 3. Predictive performance of HATCH and R-HATCH score for POAF*.

\begin{tabular}{|c|c|c|c|c|}
\hline \multirow{3}{*}{ Observed } & & \multicolumn{3}{|c|}{ Predicted } \\
\hline & & \multicolumn{2}{|c|}{ POAF } & \multirow{2}{*}{ Percentage Correct } \\
\hline & & No & Yes & \\
\hline \multirow{2}{*}{ POAF } & $\mathrm{No}$ & 72 & 16 & 81.8 \\
\hline & Yes & 38 & 52 & 57.8 \\
\hline \multicolumn{2}{|c|}{ Overall } & & & 69.7 \\
\hline & & valu & & \\
\hline
\end{tabular}

In the univariate regression analysis, each score unit of HATCH increases the risk of POAF by $97.70 \%$ $(\operatorname{Exp}(B)=1.977)[95 \% \mathrm{CI} \operatorname{EXP}(\mathrm{B}) / 1.470-2.659 /]$ $(\mathrm{p}=0.0001)$ (Fig. 3).

\section{POAF and R-HATCH score}

We derived a new R-HATCH score, by adding 1 point for renal dysfunction $(e G F R<60$ $\mathrm{ml} / \mathrm{min} / 1.73 \mathrm{~m}^{2}$ ) or 0 points for eGFR $\geq 60 \mathrm{ml} /$ $\mathrm{min} / 1.73 \mathrm{~m}^{2}$ to the original HATCH score.

An increase of R-HATCH score by a single unit increases the POAF risk by $114.70 \%(\operatorname{Exp}(B)=2.147)$ [95\%CI for $\operatorname{EXP(B)~} / 1.605-2.873 /$ ], significant for $\mathrm{p}<0.001$ ( $\mathrm{p}=0.000$ ) (Fig. 4).

\section{Multivariate binary logistic regression analysis for POAF}

The backward conditional method was used to analyse and compare the predictive role of $\mathrm{HATCH}$ score and the new derived R-HATCH score for POAF. The global accuracy of the backward conditional method is $69.70 \%$, with a sensitivity of $57.80 \%$ and a specificity of $81.80 \%$ (Table 3 ).

We have found that R-HATCH score has a significantly higher predictive power for POAF (Wald=12.920, $\mathrm{p}=0.000$ ) compared to HATCH score (Wald $=5.019, \mathrm{p}=0.025$ ) (Table 4). Each R-HATCH score elevation significantly increases the risk for POAF by $508.80 \%(\operatorname{Exp}(B)=6.088)[95 \% \mathrm{CI}$ for $\operatorname{EXP}(\mathrm{B})$ $/ 2.274-16.300 /]$ significant for $\mathrm{p}<0.001(\mathrm{p}=0.000)$.

\section{Differences in AUC of HATCH and R-HATCH scores}

The new R-HATCH scoring model improved the diagnostic accuracy in predicting POAF when compared to HATCH score. The area under the ROC curve increased from 0.731 to 0.761 ( $\mathrm{p}<0.05 / \mathrm{Z}=2.52$; $\mathrm{p}=0.01)$ (Fig. 5). 


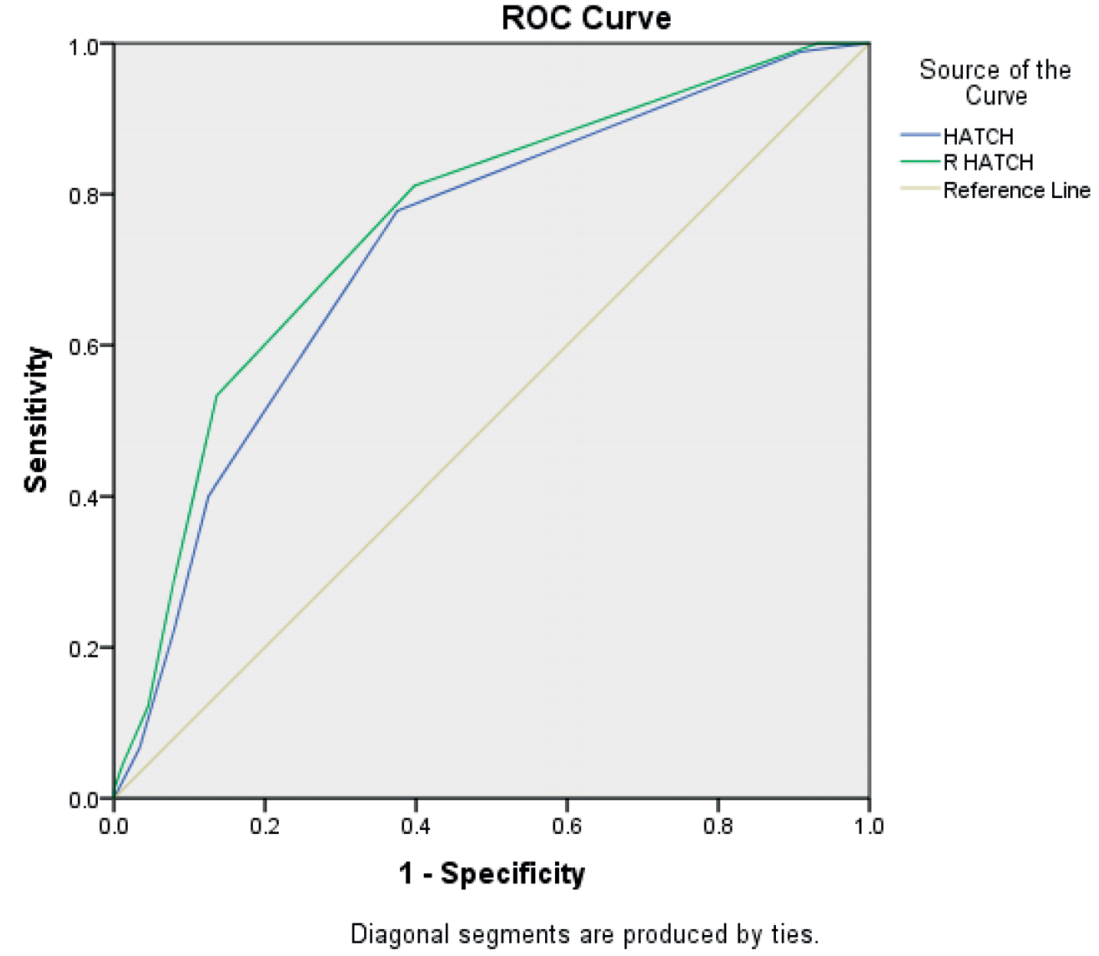

Figure 5. Comparison of ROC curves for HATCH and R-HATCH score.

Table 4. Multivariate binary logistic regression analysis for POAF/ HATCH and R-HATCH score.

\begin{tabular}{ccccccccc}
\hline & \multirow{2}{*}{ B } & S.E. & Wald & df & Sig. & \multirow{2}{*}{$\operatorname{Exp}(B)$} & \multicolumn{2}{c}{$95 \%$ CI for EXP(B) } \\
\cline { 6 - 10 } & & & & & & & Lower & Upper \\
\hline HATCH & 1.167 & 0.521 & 5.019 & 1 & 0.025 & 0.311 & 0.112 & 0.864 \\
\hline R-HATCH & 1.806 & 0.503 & 12.920 & 1 & 0.000 & 6.088 & 2.274 & 16.300 \\
\hline Constant & 1.530 & 0.340 & 20.193 & 1 & 0.000 & 0.217 & & \\
\hline
\end{tabular}

\section{Discussion}

The review of recently published studies revealed an incidence of POAF of up to $40 \%$ after $\mathrm{CABG}$ and up to $62 \%$ after combined cardiac surgery intervention $^{3}$. In our study, the POAF incidence is similar to previously published data ${ }^{1-3}$. This study, as well as other studies, did not observe a significant association between male gender and $\mathrm{POAF}^{8,9}$. As atrial fibrillation in general, POAF incidence also increases with age, and it was confirmed as an independent risk factor in our study, as well. However, previous studies have found conflicting results regarding the significance of several comorbidities. Our study found a significant association only between COPD and CKD with POAF occurrence, like several previously published studies ${ }^{11-16}$.

Different risk scoring models have been tested, but none of them reached high sensitivity and specificity for POAF prediction. Despite including some identical parameters with other risk scoring models,
HATCH score appears to be a more significant predictor, which could be attributed to older age and higher number of points assigned for heart failure. The parameters included in HATCH score have potentially an etiologic role in POAF development. On this background, the increased perioperative adrenergic stress and volume overload significantly increase the risk of POAF occurrence. HATCH score proved to be a significant independent predictor of POAF in this study, which is similar with the results of the study of Burgos et $\mathrm{al}^{17}$. ROC curve analysis shows, however, a moderate sensitivity and specificity for this scoring model.

Studies have confirmed the epidemiologic link between CKD and atrial fibrillation; however, the etiological mechanisms are yet to be elucidated ${ }^{1822}$. Both conditions share common risk factors, including hypertension, diabetes mellitus and coronary artery disease. CKD-induced activation of renin-angiotensin-aldosterone system, decreased conduction velocity, electrical and structural remodeling, stretch and fibrosis, 
specifically of left atrial tissue, are the elements of a potential pathophysiological cascade resulting in POAF $^{18,19,22,23}$. We established a strong negative linear correlation between eGFR and POAF. Therefore, we sought to determine whether the addition of this parameter could improve the diagnostic accuracy of HATCH score for POAF. The results of our study suggest that the newly derived R-HATCH scoring model has improved diagnostic accuracy in comparison to HATCH score for POAF occurrence. This remains to be confirmed in further large scale studies.

There are several limitations of this study. First, our study only included episodes of POAF detected during the hospital stay. We might have missed episodes occurring in the outpatient setting afterwards. However, the median period of POAF onset in our study is in concordance with previously published literature, where POAF was observed during the first several days postoperatively. Second, the use of MDRD formula for eGFR estimation is possibly confounded by the fact that it includes age, a well-established independent risk factor for POAF. Third, our study included CABG as well as valve surgery, meaning a heterogeneous patient population. However, all interventions included on-pump technique and only a minority were mitral valve surgeries, which is considered a major risk factor for POAF.

\section{Conclusions}

The addition of renal dysfunction (eGFR<60 $\mathrm{ml} / \mathrm{min} / 1.73 \mathrm{~m}^{2}$ ) could improve the diagnostic accuracy of the HATCH score for POAF occurrence. It is a simple and readily available clinical tool that would allow a better identification of the high-risk patient population towards whom prophylactic measures could be directed. Further large scale studies are needed to confirm these findings.

\section{Author Contributions:}

Conceptualization, M.Gj.R. and G.S.; methodology, M.Gj.R.; software, M.Gj.R.; validation, S.J.; formal analysis, G.S.; investigation, M.Gj.R and G.S.; resources, M.Gj.R.; data curation, M.Gj.R.; writing-original draft preparation, M.Gj.R.; writing-review and editing, M.Gj.R., G.S., S.J.; visualization, M.Gj.R. and G.S.; supervision, S.J . All the authors have read and agreed with the final version of the article.

\section{Compliance with Ethics Requirements:}

"The authors declare no conflict of interest regarding this article"

"The authors declare that all the procedures and experiments of this study respect the ethical standards in the
Helsinki Declaration of 1975, as revised in 2008(5), as well as the national law. Informed consent was obtained from all the patients included in the study"

"No funding for this study"

\section{Acknowledgements:}

None

\section{References}

1. Frendl G, Sodickson AC, Cheung MK, et al. American Association for Thoracic Surgery. 2014 AATS guidelines for the prevention and management of perioperative atrial fibrillation and flutter for thoracic surgical procedures. $J$ Thorac Cardiovasc Surg. 2014;148(3):e153-93.

2. Rezaei Y, Peighambari NM, Naghshambari MM, et al. Postoperative atrial fibrillation following cardiac surgery: from pathogenesis to potential therapies. Am J Cardiovasc Drugs. 2020;20(1):19-49.

3. Gudbjartsson T, Helgadottir S, Sigurdsson MI, et al. New-onset postoperative atrial fibrillation after heart surgery. Acta Anaesthesiol Scand. 2020;64(2):145-155.

4. Almassi GH, Pecsi SA, Collins JF, et al. Predictors and impact of postoperative atrial fibrillation on patients' outcomes: a report from the Randomized On Versus Off Bypass trial. J Thorac Cardiovasc Surg. 2012;143(1):93-102.

5. Aranki SF, Shaw DP, Adams Dh, et al. Predictors of atrial fibrillation after coronary artery surgery: current trends and impact on hospital resources. Circulation.1996;94:390-397.

6. Mathew JP, Fontes ML, Tudor IC, et al. A multicenter risk index for atrial fibrillation after cardiac surgery. JAMA 2004:291:1720-9.

7. Maisel WH, Rawn JD, Stivenson WG, et al. Atrial fibrillation after cardiac surgery. Ann Intern Med 2001;135:1061-73.

8. Creswell LL, Schuessler RB, Rosenbloom M, Cox Jl. Hazards of postoperative atrial arrhythmias. Ann Thorac Surg. 1993;56:539-549.

9. Frost L, Molgaard H, Christiansen EH, et al. Atrial ectopic activity and atrial fibrillation/fiutter after coronary artery bypass surgery; a case-base study controlling for the confounding from age, $\beta$-blocker treatment, and the time distance from operation. Int J Cardiol. 1995;50:153-162.

10. Amar $\mathrm{D}$, Zhang $\mathrm{H}$, Leung $\mathrm{D}$, et al. Older age is the strongest predictor of postoperative atrial fibrillation. Anesthesiology. 2002;96:352-6.

11. Cameron MJ, Tran DT, Abboud J, et al. Prospective external validation of three preoperative risk scores for prediction of new onset atrial fibrillation after cardiac surgery. Anesth Analg. 2018;126(1):33-38.

12. De Vos CB, Pisters R, Nieuwlaat R, et al. Progression from paroxysmal to persistent atrial fibrillation: clinical correlates and prognosis. J Am Coll Cardiol. 2010; 55: 725-731.

13. Levey AS, Bosch JP, Lewis JB, et al. A more accurate method to estimate glomerular filtration rate from serum creatinine: a new prediction equation. Modification of Diet in Renal Disease Study Group. Ann Intern Med 1999;130: 461 -70.

14. Yin L, Ling X, Zhang Y, et al. VASc scoring systems for predicting atrial fibrillation following cardiac valve surgery. PLoS One. 2015;10(4).

15. Franczyk B, Gluba-Brzoska A, Cialkowska-Rysz A, et al. The problem of atrial fibrillation in patients with chronic kidney disease. Curr Vasc Pharmacol. 2016;14(3):260-65. 
16. Alonso A, Lopez FL, Matsushita K, et al. Chronic kidney disease is associated with the incidence of atrial fibrillation. The Atherosclerosis Risk in Communities (ARIC) Study. Circulation. 2011;28(123(25)):2946-53

17. Burgos LM, Parodi JB, Espinoza J, et al. Predicting postoperative atrial fibrillation after cardiac surgery: validation and comparison of CHA2DS2-VASc, POAF and HATCH risk scoring systems. European Heart Journal. 2017;38 (Suppl 1).

18. Chua SK, Shyu KG, LU MJ, et al. Renal dysfunction and the risk of postoperative atrial fibrillation after cardiac surgery: role beyond the $\mathrm{CHA}_{2} \mathrm{DS}_{2}$-VASc score. Europace. 2015;17(9):1363-70.

19. Violi F, Soliman ZE, Pignatelli P, et al. Atrial fibrillation and myocardial infarction: a systematic review and appraisal of pathophysiologic mechanisms. Journal of the American Heart Association. 2016;5:e03347.

20. Hashemzadeh K, Dehdilani M. Postoperative atrial fibrillation following open cardiac surgery: predisposing factors and complications. J Cardiovasc Thorac Res. 2013;5(3):101-7.

21. Manea M, Marcu D, Pantea Stoian A, et al. Heart failure with preserved ejection fraction and atrial fibrillation: a review. Rev Chim (Bucharest) 2018;69(11):4180-4184.

22. Moisi M.I, Bungau SG, Vesa CM, et al. Framing cause-effect relationship of acute coronary syndrome in patients with chronic kidney disease. Diagnostics 2021;11(8):1518.

23. Diaconu C, Balaceanu A. Atrial fibrillation and comorbidities in very elderly patients. Arch Balk Med Union 2015;50(2):190-193. 